\title{
Novel hydrophilic-hydrophobic block copolymer based on cardo poly(arylene ether sulfone)s with bis-quaternary ammonium moieties
}

\section{for anion exchange membranes}

Xue Dong a, b, Shuhua Hou ${ }^{\text {a }}$, Hongchao Mao a, Jifu Zheng a, *, Suobo Zhang a, c, *

${ }^{a}$ Key Laboratory of Polymer Ecomaterials, Changchun Institute of Applied Chemistry, Chinese Academy of Sciences, 5625 Renmin Street, Changchun 130022, China

${ }^{\mathrm{b}}$ University of Chinese Academy of Sciences, Beijing 100049, China

${ }^{\mathrm{c}}$ Jiangsu National Synergetic Innovation Center for Advanced Materials (SICAM)

\section{Abstract}

Two types of phenolphthalein-based copolymers, random and block cardo poly(aryl ether sulfone)s with pendant tertiary amine groups were synthesized via copolycondensation. Both of the copolymers were grafted with (3-bromopropyl) trimethylammonium bromide to prepare anion exchange membranes with bis-quaternary ammonium groups for hydroxide ion conductivity measurements. The block anion exchange membrane QBPES-60 with an ion exchange capacity (IEC) of $1.93 \mathrm{mmol} \mathrm{g} \mathrm{g}^{-1}$ exhibited higher ionic conductivity $\left(40.5 \mathrm{mS} \mathrm{cm}{ }^{-1}\right)$ in water at $60{ }^{\circ} \mathrm{C}$ than the random copolymer QRPES-60 $\left(30.0 \mathrm{mS} \mathrm{cm}^{-1}\right)$ under the same conditions. Small-angle X-ray scattering and transmission electron microscopy suggested the membrane constructed from the block polymer exhibited a more obvious phase-separated structure and formed ion clusters which would be responsible for the high conductivity. Moreover, the block anion exchange membrane with bis-quaternary

\footnotetext{
* Corresponding author. Tel: (86) 431-85262117. Fax: (86) 431-85262117.

E-mail address jfzheng@ciac.ac.cn (j,Zheng): sbzhang@ciac.ac.cn (s.Zhang).
} 
ammonium groups showed better alkaline stability than the random membrane where degradation could be recognized by ${ }^{1} \mathrm{H}$ NMR spectra as well as ion conductivities. In conclusion, integrating the block hydrophilic bis-quaternary ammonium ion groups along with the long aliphatic side chains, and the hydrophobic copolymer backbone, this synthetic strategy is promising to prepare AEMs with high conductivity and good alkaline stability.

\section{Introduction}

Alkaline membrane fuel cells (AMFCs) have recently received widespread attention among scientists because of their apparent property advantages. Compared with traditional proton-exchange membrane fuel cells (PEMFC), AMFCs, operated in alkaline conditions, own faster oxygen reduction kinetics and fuel oxidation kinetics in alkaline media, enabling the utilization of non-precious metal catalysts (e.g. cobalt, silver, nickel) and high cell efficiencies [1-4]. Anion exchange membranes (AEMs), the critical component of AMFCs to transport hydroxide ions from the cathode to the anode, have been rapidly developed over the past decade. To date, the design of AEMs materials in AMFCs has mainly focused on quaternary ammonium, quaternary phosphonium or guanidinium functionalized polymers, such as poly(arylene ether sulfone) [5-7], poly(arylene ether ketone) [8-10], poly(arylene ether)s [11, 12], poly(phenylene oxide)s [13-15] and poly(phenylene)s [16, 17]. The primary challenge to realize the commercialization of AEMs is to prepare membrane materials with adequate mechanical strength, superior ionic conductivity and necessary stability under alkaline fuel cells operating conditions. However, the application of AEMs is 
still limited due to its low hydroxide conductivity for $\mathrm{OH}^{-}$in contrast with $\mathrm{H}^{+}$ conductivity in proton exchange membranes (PEMs) [18-21].

So far, several strategies have been developed for the design and synthesis of polymers to prepare highly anion-conducting membrane materials. One of the most attractive methods is the preparation of multi-block copolymers composed of quaternary hydrophilic groups as well as hydrophobic groups [17, 22-24]. The quaternary ion groups make up multiplets to aggregate into larger clusters which are embedded in hydrophobic domains and promote the formation of micro-phase separation. Through the phase-separation morphologies, this copolymer membrane structure leads to the formation of interconnected ionic channels and shows higher hydroxide ion conductivity than their corresponding random copolymers. Miyatake et al synthesized anion conductive aromatic multiblock poly(arylene ether)s copolymers in which the formed hydrophobic/hydrophilic phase separation morphology and the interconnected ion transporting pathway effectively improved hydroxide ion conductivity up to $144 \mathrm{mS} \mathrm{cm}-1$ at $80{ }^{\circ} \mathrm{C}$ [22]. Other methods to improve hydroxide ion conductivity include the adjustment of ion group density and distribution, as well as the incorporation of more flexible and longer aliphatic chains [20, 25-28]. The multi-functionalized and flexible quaternary ammonium hydrophilic domains further promote a more apparent cluster-like segment and longer hydrophobic segment. For example, $\mathrm{Xu}$ et al synthesized a series of polymers that were grafted with more flexible and multi-functionalized side chains containing multiple hydrophilic quaternary ammonium groups. They demonstrated that the designed flexible side 
chain polymer structure apparently facilitated the formation of hydrophilic-hydrophobic micro-phase separation, and correspondingly improved $\mathrm{OH}^{-}$ conductivity, dimensional stability and alkaline stability [27].

In regards to the fabrication and development of AEMs, high-performance membranes are also desirable. Previously, our group has synthesized phenolphthalein-based cardo poly(aryl ether sulfone)s with quaternary amine groups on aliphatic side chains as hydroxide ion conductive materials. The synthesis of the polymer avoided the chloromethylation process and extended a novel method to prepare anion membrane materials [29]. Moreover, phenolphthalein, one type of cardo group, was designed in the polymer because this bulky and fully aromatic structure provides certain thermal stability and mechanical properties to membranes. The prepared anion exchange membrane with an IEC value of 1.5 mequiv. $\mathrm{g}^{-1}$ showed ionic conductivity of $30.0 \mathrm{mS} \mathrm{cm}{ }^{-1}$ at $60{ }^{\circ} \mathrm{C}$. On the basis of this polymer structure, we are motivated to further design a novel copolymer with block as well as flexible and multifunctional aliphatic side chains to improve membrane performance as it can be confirmed that the combination of block and bis-quaternary ammonium structure are effective manners to improve ionic conductivity and alkaline stability.

In this manuscript, two types of copolymers, random and block cardo poly(aryl ether sulfone)s with pendant tertiary amine groups were synthesized. Both of copolymers were grated with bis-quaternary ammonium groups in a certain length for aliphatic side chains to improve the density and flexibility of hydrophilic ionic segments. The corresponding anion exchange membranes based on these two copolymers were 
prepared and ion conductivity, mechanical properties, water uptake, swelling ratio, morphology as well as alkaline stability were investigated. In contrast to the membrane built by random copolymer, the membrane constructed from block copolymer with hydrophilic bis-quaternary ammonium ion groups and long aliphatic side chains is expected to exhibit high conductivity and good alkaline stability.

\section{Experimental}

\subsection{Materials and reagents}

Synthesis of 2-(3-(dimethylamino) propyl)-3, 3'- bis (4-hydroxyphenyl) isoindolin-1one (PPH-DMPA) was prepared as we reported previously [29]. 4, 4'-Difluorodiphenylsulfone (DFDPS), (3-bromopropyl) trimethylammonium bromide and bisphenol A (BPA) were purchased from Sinopharm Group Chemical Reagent. Dimethylsulfoxide (DMSO) and dimethylacetamide (DMAc) were dried over $\mathrm{CaH}_{2}$ and distilled under reduced pressure before use. All other reagents were obtained from commercial sources and used as received. 


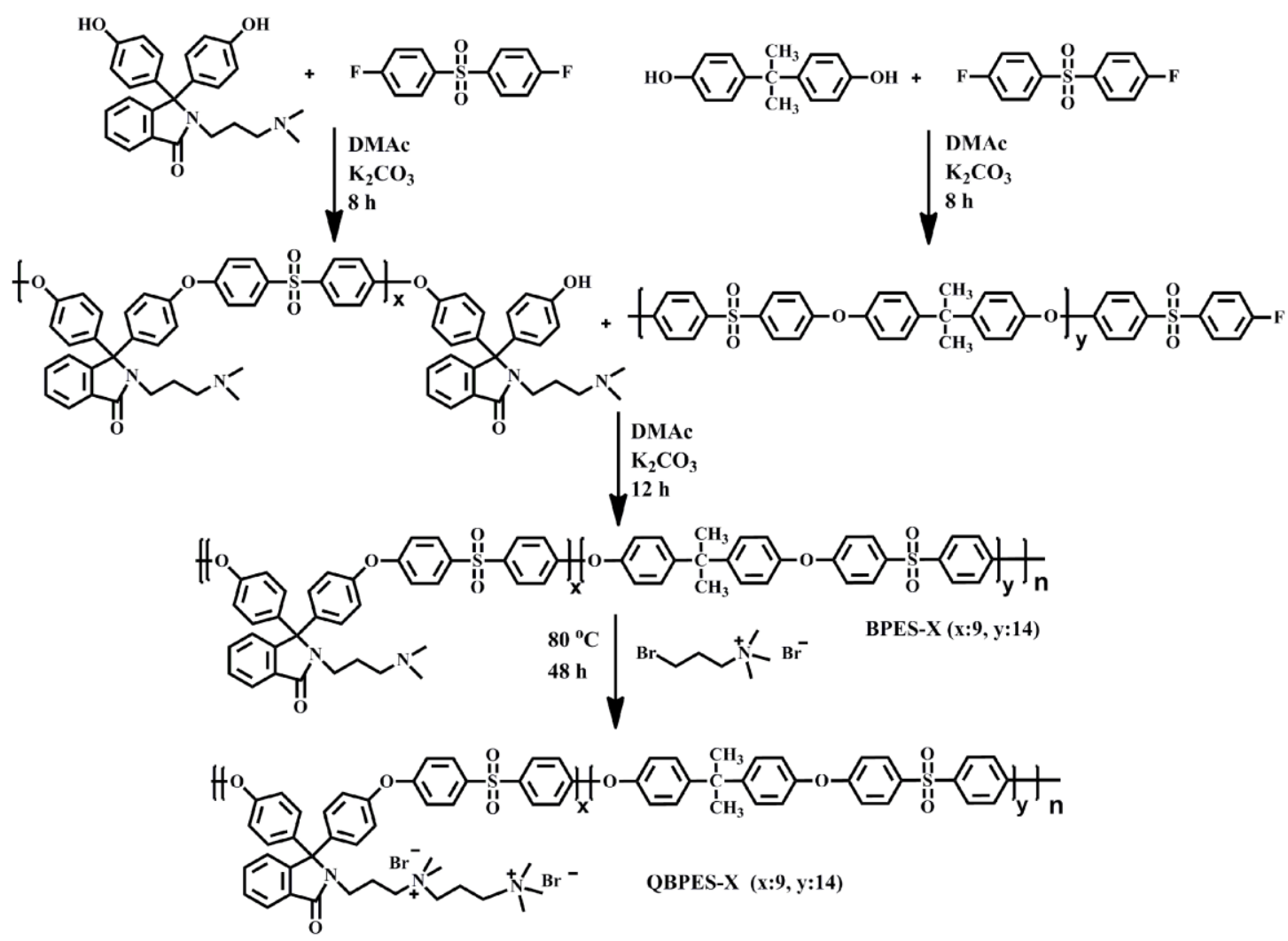

Scheme.1 Synthesis of block cardo poly(arylene ether sulfone)s with pendant bis-quaternary ammonium groups QBPES-X.

2.2 Synthesis of block poly(arylene ether sulfone)s with pendant tertiary amine groups BPES-60.

The block copolymers were synthesized following the procedure in Scheme 1: A dried $250 \mathrm{~mL}$ three-necked flask equipped with a nitrogen inlet, a Dean-Stark trap with a condenser and a mechanical stirrer was charged with PPH-DMPA (12.07g, 30 mmol), DFDPS (6.86 g, $27 \mathrm{mmol})$, anhydrous $\mathrm{K}_{2} \mathrm{CO}_{3}(7.46 \mathrm{~g}, 54 \mathrm{mmol})$, DMAc $90 \mathrm{~mL}$ and $25 \mathrm{~mL}$ toluene. The mixture was heated to reflux at $140{ }^{\circ} \mathrm{C}$ for $8 \mathrm{~h}$. The toluene and water were removed from the mixture by azeotropic distillation. The reaction mixture was gradually raised to $180{ }^{\circ} \mathrm{C}$ and heated for $12 \mathrm{~h}$. Another experiment using a dried $100 \mathrm{~mL}$ three-necked flask and same conditions was performed, using DFDPS (5.85 g, 
$23 \mathrm{mmol}$ ), BPA (4.56 g, $20 \mathrm{mmol})$, anhydrous $\mathrm{K}_{2} \mathrm{CO}_{3}(5.53 \mathrm{~g}, 40 \mathrm{mmol}), 50 \mathrm{~mL}$ DMAc as well as $15 \mathrm{~mL}$ toluene. Then obtained two oligomers were mixed after being cooled to room temperature. The mixture was reacted at $180{ }^{\circ} \mathrm{C}$ for $12 \mathrm{~h}$ to obtain a viscous polymer solution. After cooling to room temperature, the mixture was diluted with $20 \mathrm{~mL}$ DMAc and poured into $70{ }^{\circ} \mathrm{C}$ water to obtain the pure polymer. The polymer was dried under vacuum at $120{ }^{\circ} \mathrm{C}$ for $20 \mathrm{~h}$. The block poly(arylene ether sulfone)s with pendant tertiary amine groups was named BPES-60.

2.3 Synthesis of random poly(arylene ether sulfone)s with pendant tertiary amine groups RPES-60.

The random copolymers, named as RPES-60, with same molar ratio of PPH-DMPA to BPA were synthesized under the same experimental equipments as above. A dried 250 $\mathrm{mL}$ three-necked flask equipped with a nitrogen inlet, a Dean-Stark trap with a condenser and a mechanical stirrer was charged with PPH-DMPA (12.07g, $30 \mathrm{mmol})$, BPA (4.56 g, $20 \mathrm{mmol})$, DFDPS (12.71 g, $50 \mathrm{mmol})$, anhydrous $\mathrm{K}_{2} \mathrm{CO}_{3}(11.06 \mathrm{~g}, 80$ mmol), $140 \mathrm{~mL}$ DMAc, and $50 \mathrm{~mL}$ toluene. The mixture was heated to reflux at 140 ${ }^{\circ} \mathrm{C}$ for $8 \mathrm{~h}$, after which toluene and water were removed from the mixture by azeotropic distillation. The mixture was heated to $180{ }^{\circ} \mathrm{C}$ for $12 \mathrm{~h}$ to obtain a viscous polymer solution. After the solution was cooled to room temperature, the mixture was diluted with $20 \mathrm{~mL}$ DMAc, filtered and poured into $70{ }^{\circ} \mathrm{C}$ water to obtain the pure polymer. The obtained copolymer was dried under vacuum at $120{ }^{\circ} \mathrm{C}$ for $20 \mathrm{~h}$.

2.4 Synthesis of bis-quaternary ammonium cardo poly(aryl ether sulfone)s QBPES-60 and QRPES-60 
Synthesis of block and random cardo poly(aryl ether sulfone)s containing alkyl ammonium groups are described as follows: copolymer BPES-60 or RPES-60 (2.16 g, $40 \mathrm{mmol}$ ) and $15 \mathrm{~mL}$ DMSO were added to a reaction flask. Once the mixture formed a homogeneous solution, (3-bromopropyl) trimethylammonium bromide (36 g, 60 mmol) was added and the mixture was stirred at $80{ }^{\circ} \mathrm{C}$ for $48 \mathrm{~h}$. The mixture was poured into ethanol and washed several times. The polymer was then dried in a vacuum oven for $12 \mathrm{~h}$ at $100{ }^{\circ} \mathrm{C}$. The bis-quaternary ammonium block and random cardo poly(aryl ether sulfone)s were named QBPES-60 and QRPES-60, respectively.

\subsection{Membrane preparation}

The bis-quaternary ammonium copolymer $(0.70 \mathrm{~g}, 1 \mathrm{mmol})$ was dissolved in $18 \mathrm{~mL}$ DMSO. The solution was filtered using a $0.45 \mathrm{~mm}$ Teflon syringe and cast onto a clean and flat glass plate. The membrane was dried in an oven at $80{ }^{\circ} \mathrm{C}$ for $12 \mathrm{~h}$, and at $120{ }^{\circ} \mathrm{C}$ under vacuum for $24 \mathrm{~h}$ to remove the casting solvent. After the membrane was peeled off from the glass plate, the membrane was stored in $1 \mathrm{~mol} \mathrm{~L}^{-1} \mathrm{NaOH}$ aqueous solution for two days to obtain the membrane in the $\mathrm{OH}^{-}$form. Finally, the membrane was wash several times and immersed in deionized water at $60{ }^{\circ} \mathrm{C}$ for $48 \mathrm{~h}$ to remove residual $\mathrm{NaOH}$. The bis-quaternary ammonium membrane was kept in deionized water before used.

\subsection{Measurement}

${ }^{1} \mathrm{H}$ NMR spectra was measured on a Varian Unity spectrometer at $500 \mathrm{MHz}$ at $30{ }^{\circ} \mathrm{C}$ using tetramethylsilane (TMS) as the internal standard and DMSO- $d_{6}$ as the solvent. 
The copolymer solution viscosity was determined using an Ubbelohde capillary viscometer in DMAc at $30 \pm 0.1{ }^{\circ} \mathrm{C}$. Mechanical properties were measured with a mechanical tester Instron-1211 instrument (Instron Co, USA) at a speed of $5 \mathrm{~mm}$ $\min ^{-1}$ at ambient temperature. The thermal stability of the membranes was measured by thermo gravimetric analysis (TGA) (Perkin Elmer TGA-2) under nitrogen at the heating rate of $10^{\circ} \mathrm{C} \mathrm{min}^{-1}$.

The theoretical IEC represented the millimole quantity of ionic functional groups in 1 g polymer, and is calculated according to Eq. (1).

$\operatorname{IEC}_{\mathrm{T}}\left(\frac{\mathrm{mmol}}{\mathrm{g}}\right)=\frac{\mathrm{X} \times 1000}{\mathrm{M}}$

where $\mathrm{X}$ represents the ratio of monomer with ionic functional groups in polymer, and $\mathrm{M}$ represents the molar mass of polymer.

The experimental IEC was determined by titrations. $0.5 \mathrm{~g}$ membranes in the $\mathrm{OH}^{-}$form were immersed in $100 \mathrm{~mL}$ of $0.1 \mathrm{M} \mathrm{HCl}$ standard for $48 \mathrm{~h}$ to keep adequate exchange for $\mathrm{OH}^{-}$and $\mathrm{Cl}^{-}$. The solution was then titrated with a standardized $0.1 \mathrm{M} \mathrm{NaOH}$ solution using phenolphthalein as an indicator and the volume of titrated $\mathrm{NaOH}$ is labeled as Y. The experimental IEC is calculated from Eq. (2)

$\operatorname{IEC}_{\mathrm{E}}\left(\frac{\mathrm{mmol}}{\mathrm{g}}\right)=\frac{(100-\mathrm{Y}) \times 0.1}{0.5}$

The water uptake was measured by placing the anion exchange membrane that was dried under vacuum at $120^{\circ} \mathrm{C}$ for $16 \mathrm{~h}$ into deionized water for $4 \mathrm{~h}$. The membrane was taken out and wiped with tissue paper and immediately weighed on a microbalance. Water uptake was calculated from Eq. (3)

Water uptake $(\%)=\frac{\mathrm{w}_{\mathrm{w}}-\mathrm{W}_{\mathrm{d}}}{\mathrm{w}_{\mathrm{d}}} \times 100$ 
where $\mathrm{W}_{\mathrm{w}}$ and $\mathrm{W}_{\mathrm{d}}$ represent the weights of wet and dry membrane, respectively.

The swelling ratio represents the dimensional change for dry and wet membranes. The changes in length were measured from Eq. (4)

Swelling ratio $(\%)=\frac{\mathrm{L}_{\mathrm{w}}-\mathrm{L}_{\mathrm{d}}}{\mathrm{L}_{\mathrm{d}}} \times 100$

where $L_{d}$ and $L_{w}$ are the length of dry and wet membrane, respectively.

Small-angle scattering measurements were obtained on Beamline 4B9A at the Beijing Synchrotron Radiation Facility (BSRF). The film samples with surfaces perpendicular to the X-ray beam were directly positioned in the optical path of the X-ray beam. The data was collected using a CCD detector (MAR) with a maximum resolution of 3450 x 3450 pixels. The X-ray wavelength was $1.384 \AA$, and the energy of the X-ray was $8.98 \mathrm{keV}$. A single exposure of $200 \mathrm{~s}$ was used to obtain the scattering data.

To obtain transmission electron microscopy (TEM) images with apparent hydrophilic segments and hydrophobic segments, all the membranes were dyed with $\mathrm{PtCl}_{6}{ }^{2-}$ by anion exchange. The polymer solution in $5 \mathrm{mg} \mathrm{mL}^{-1}$ was dropped on a copper grid and dried at $80{ }^{\circ} \mathrm{C}$ for $12 \mathrm{~h}$. The copper grid doped with polymer membrane was then immersed into a $\mathrm{H}_{2} \mathrm{PtCl}_{6}$ aqueous solution for 10 min to exchange the membrane $\mathrm{Br}^{-}$ ions into $\mathrm{PtCl}_{6}^{2-}$ ions. Finally, the dyed copper grid was rinsed with deionized water several times to remove the residual salt solution and dried at room temperature prior to TEM measurements. The TEM images were taken on an ultra high-resolution transmission electron microscope (JEOLJEM-2010FEF) using an accelerating voltage of $200 \mathrm{kV}$.

The hydroxide conductivities $\left(\sigma, \mathrm{mS} \mathrm{cm}^{-1}\right)$ for the whole anion exchange membranes 
$(1 \mathrm{~cm} \times 4 \mathrm{~cm})$ were obtained using the equation $\sigma=\mathrm{d} / \mathrm{LsWsR}$ where $\mathrm{d}$ represents distance between reference electrodes, and Ls as well as Ws are the thickness and width of the membrane, respectively. The conductivity measurements were conducted under previously published conditions [30]. Ohmic resistance (R) was measured using four-point probe alternating current (ac) impedance spectroscopy with an electrode system connected with an impedance/gain-phase analyzer (Solartron 1260) and an electrochemical interface (Solartron 1287, Farnborough Hampshire, ONR, UK). Before measurement, the membranes were sandwiched between two pairs of gold-plate electrodes. The electrodes and the membranes were set in a Teflon cell and the distance between the reference electrodes was $1 \mathrm{~cm}$. The cell was placed in a thermo-controlled chamber in liquid water for measurement. Conductivity measurements under fully hydrated conditions were carried out with the cell immersed in liquid water. All samples were equilibrated in water for at least $24 \mathrm{~h}$ prior to measurement. At a given temperature, the samples were equilibrated for at least 30 min before any measurements. Repeated measurements were then taken at a given temperature with $10 \mathrm{~min}$ intervals until no change in conductivity was observed.

The chemical stability of the QBPES-60 and QRPES-60 copolymer membranes was assessed by measuring the variation in both ionic conductivity and ${ }^{1} \mathrm{H}$ NMR spectra. All the membrane samples were soaked in $1 \mathrm{~mol} \mathrm{~L}^{-1} \mathrm{NaOH}$ solutions at $60{ }^{\circ} \mathrm{C}$ for a defined time. Prior to conductivity and ${ }^{1} \mathrm{H}$ NMR measurements, all the membranes were washed with deionized water several times and kept in water for two days to 
remove $\mathrm{OH}^{-}$absorbed inside the membranes.

Performance tests for a single cell were conducted according to the literature [31]. Three milligram per square centimeter PtRu/C (with 40 wt $\% \mathrm{Pt}$ and $\mathrm{Ru}$ atomic ratio of Pt to $\mathrm{Ru}^{1 / 41: 1),} 1.8 \mathrm{mg} \mathrm{cm}^{-2}$ Nafion (5 wt\% Nafion solution) were dispersed in an aqueous solution of isopropyl alcohol with ultrasonic treatment. After the suspension was uniformly dispersed, we sprayed it onto carbon paper to form the anode. The cathode was formed by spraying $3.0 \mathrm{mg} \mathrm{cm}^{-2} \mathrm{Pt} / \mathrm{C}$ (with $40 \mathrm{wt} \% \mathrm{Pt}, 1.8 \mathrm{mg} \mathrm{cm}{ }^{-2}$ Nafion as a binding agent) onto carbon paper. The effective electrode area of the single cell was $9 \mathrm{~cm}^{2}$. The performance of the single cell was measured at $40{ }^{\circ} \mathrm{C}$ with a Fuel Cell Test System (Arbin Co.). 2.0 $\mathrm{M} \mathrm{CH}_{3} \mathrm{OH}$ solution+2.0 M NaOH with a flow rate of $5 \mathrm{~mL} \mathrm{~min}-\mathrm{L}$ and oxygen with a flow rate of $100 \mathrm{~mL} \mathrm{~min}^{-1}$ at $0.05 \mathrm{MPa}$ were used. Each single cell was operated for three times.

\section{Results and discussion}

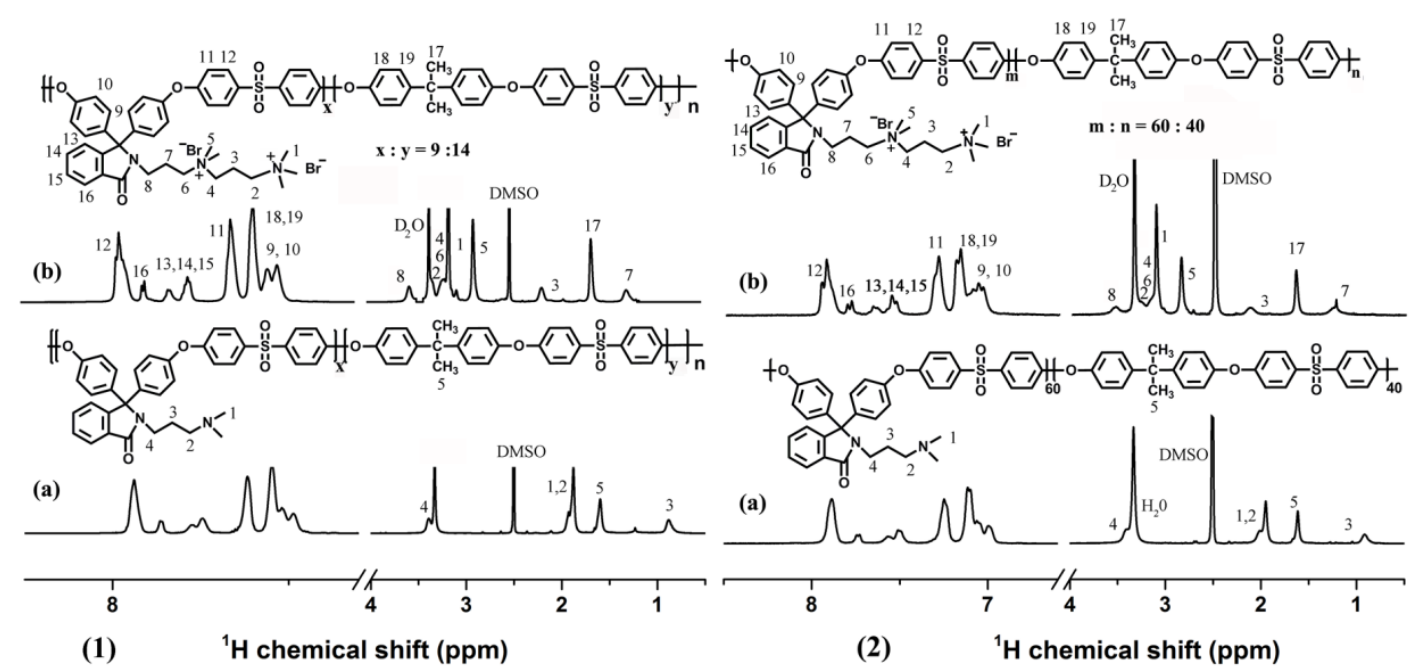

Fig. $1{ }^{1} \mathrm{H}$ NMR spectra for copolymers (1) (a) BPES-60 and (b) QBPES-60 (2) (a) RPES-60 and (b) QRPES-60.

\subsection{Synthesis and characterization of the copolymer}


The synthetic procedure of block poly(arylene ether sulfone)s is shown in Scheme 1. Two oligomers were synthesized respectively, and then mixed together to obtain the final block copolymer. Fig. 1 (1) shows the ${ }^{1} \mathrm{H}$ NMR spectra of QBPES-60 and BPES-60. All of the ${ }^{1} \mathrm{H}$ NMR signals of BPES-60 were assigned correspondingly. In particular, the chemical shift signals of $\mathrm{H}_{3}(\delta 0.88 \mathrm{ppm}), \mathrm{H}_{2}(\delta 1.93 \mathrm{ppm})$ and $\mathrm{H}_{4}(\delta$ $3.40 \mathrm{ppm})$ were assigned to the methylene protons in BPES-60. $\mathrm{H}_{1}(\delta 1.87 \mathrm{ppm})$ was assigned to methyl protons in the tertiary amine functional groups and $\mathrm{H}_{5}(\delta 1.62 \mathrm{ppm})$ was assigned to the methyl protons in bisphenol A. QBPES-60 showed variation in the high field ${ }^{1} \mathrm{H}$ NMR spectra due to the electron withdrawing effect of the quaternary ammonium groups. $\mathrm{H}_{5}(\delta 2.89 \mathrm{ppm})$ and $\mathrm{H}_{1}(\delta 3.15 \mathrm{ppm})$ were assigned to the chemical shifts of the methyl groups protons in the quaternary ammonium functional group. $\mathrm{H}_{2}(\delta 3.31 \mathrm{ppm}), \mathrm{H}_{4}(\delta 3.21 \mathrm{ppm}), \mathrm{H}_{6}(\delta 3.21 \mathrm{ppm}), \mathrm{H}_{8}(\delta 3.56 \mathrm{ppm})$, $\mathrm{H}_{3}(\delta 2.16 \mathrm{ppm})$ and $\mathrm{H}_{7}(\delta 1.29 \mathrm{ppm})$ were assigned to the chemical shifts of methylene protons.

The random poly(arylene ether sulfone)s were prepared by polycondensation of PPH-DMPA, BPS and DFDPS. The ${ }^{1} \mathrm{H}$ NMR spectra of RPES-60 and QRPES-60 are shown in Fig. 1 (2). The ${ }^{1} \mathrm{H}$ NMR spectra of RPES-60 and QRPES-60 showed similar changes as exhibited in QBPES-60: As shown in Fig. 1 (2) (a), $\mathrm{H}_{3}(\delta 0.91 \mathrm{ppm}), \mathrm{H}_{2}(\delta$ $2.02 \mathrm{ppm})$ and $\mathrm{H}_{4}(\delta 3.41 \mathrm{ppm})$ were assigned to the methylene protons in RPES-60. $\mathrm{H}_{1}(\delta 1.95 \mathrm{ppm})$ was assigned to methyl protons in the tertiary amine functional groups, and $\mathrm{H}_{5}(\delta 1.62 \mathrm{ppm})$ was assigned to the methyl protons in bisphenol A. For QRPES-60 copolymer in Fig. 1 (2) (b), $\mathrm{H}_{5}(\delta 2.86 \mathrm{ppm})$ and $\mathrm{H}_{1}(\delta 3.12 \mathrm{ppm})$ were 
assigned to the chemical shifts of the methyl groups protons in the quaternary ammonium functional group and $\mathrm{H}_{2}(\delta 3.27 \mathrm{ppm}), \mathrm{H}_{4}(\delta 3.17 \mathrm{ppm}), \mathrm{H}_{6}(\delta 3.17 \mathrm{ppm})$, $\mathrm{H}_{8}(\delta 3.55 \mathrm{ppm}), \mathrm{H}_{3}(\delta 2.12 \mathrm{ppm})$ as well as $\mathrm{H}_{7}(\delta 1.25 \mathrm{ppm})$ were assigned to the chemical shifts of methylene protons.

In addition, the high-resolution XPS scan for $N$ 1s can be used to probe for $\mathrm{N}$ element in tertiary amines as well as quaternary ammonium groups in the polymers. As shown in Fig. 2, the XPS spectra for QBPES-60 and QRPES-60 exhibited peaks for $N$ (399 $\mathrm{eV})$ in tertiary amines and $N^{+}(402 \mathrm{eV})$ in quaternary ammonium, with peak area proportional to $1: 2$. Consequently, it could be confirmed from the XPS spectra that both copolymers were grafted with bis-quaternary ammonium side chains in the quaternary ammonium process.

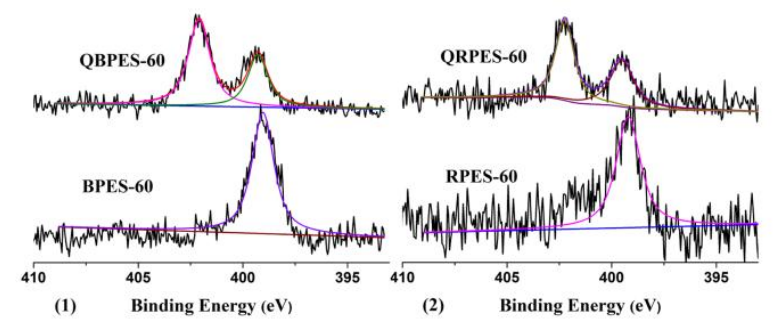

Fig. 2 XPS spectra for (1) BPES-60 and QBPES-60 (2) RPES-60 and QRPES-60.

Table 1

Inherent viscosity, IEC and mechanical properties of QBPES-60 and QRPES-60 membranes.

\begin{tabular}{ccccc}
\hline Sample & $\begin{array}{c}\eta_{\text {inh }}{ }^{\mathrm{b}} \\
\left(\mathrm{dL} \mathrm{g}^{-1}\right)\end{array}$ & $\begin{array}{c}\text { Tensile strength } \\
(\mathrm{MPa})\end{array}$ & $\begin{array}{c}\text { Tensile modulus } \\
(\mathrm{GPa})\end{array}$ & $\begin{array}{c}\text { Elongation at break } \\
(\%)\end{array}$ \\
\hline QBPES-60 & 0.75 & 26.4 & 0.7 & 6.3 \\
QRPES-60 & 0.82 & 34.0 & 1.1 & 4.8 \\
\hline
\end{tabular}

a Samples were dried at ambient conditions for one day and tested at $30^{\circ} \mathrm{C}$ and ambient humidity conditions.

${ }^{\mathrm{b}}$ Inherent viscosity measured at a concentration of $0.5 \mathrm{~g} \mathrm{dL}^{-1}$ in DMAc at $30^{\circ} \mathrm{C}$.

3.2 Mechanical properties and thermal properties of QBPES-60 and QRPES-60 
The mechanical properties of AEMs are important characterization parameters when evaluating the membrane potential application in alkaline fuel cells. The mechanical properties of QBPES-60 and QRPES-60 were measured at room temperature and 30\% $\mathrm{RH}$, and the results were shown in Table 1. QBPES-60 exhibited tensile strength of 26.4 MPa, elongation at break of $6.3 \%$ and Young's modulus of $0.7 \mathrm{GPa}$. And QRPES-60 exhibited tensile strength of $34.0 \mathrm{MPa}$, elongation at break of $4.8 \%$ and Young's modulus of $1.1 \mathrm{GPa}$. Judging from the mechanical analysis, it can be concluded that two types of membranes met the required mechanical properties for AMFCs application.

The TGA curves of QBPES-60 and QRPES-60 membranes were obtained under a nitrogen atmosphere from 50 to $700{ }^{\circ} \mathrm{C}$. As shown in Fig. 4, the first stage of degradation from 200 to $450{ }^{\circ} \mathrm{C}$ is assigned to the degradation of the quaternary ammonium side chain. The second stage of degradation above $450{ }^{\circ} \mathrm{C}$ is attributed to the decomposition of the copolymer main chain. All the membranes exhibit good thermal stability and meet the application in AMFCs.

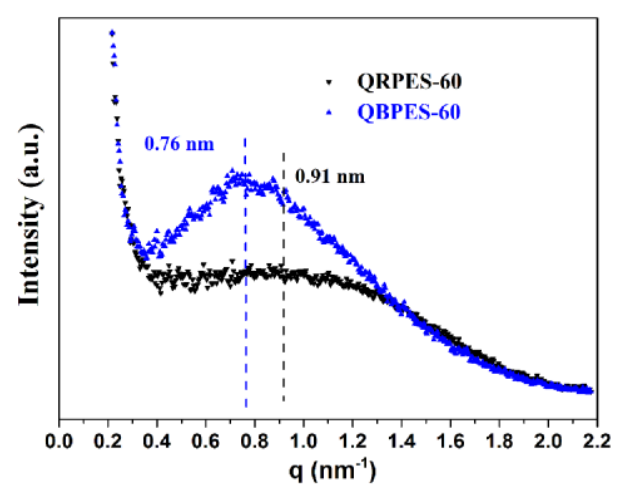

Fig. 3 SAXS profiles of QRPES-60 and QBPES-60. 


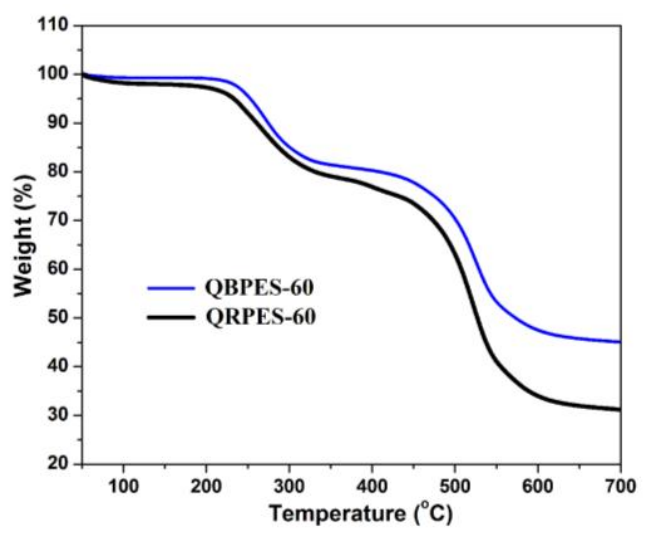

Fig. 4 The TGA curves of QBPES-60 and QRPES-60 membranes.

\subsection{The small-angle X-ray scattering (SAXS) and membrane Morphology}

Transparent as well as mechanically stable AEMs were prepared by casting polymer solutions in DMSO. The membranes with the counter ion of $\mathrm{PtCl}_{6}{ }^{2-}$ and a final thickness of $30 \mu \mathrm{m}$ were investigated using small-angle X-ray scattering (SAXS) in order to determine their ability to form a microphase separation structure. As shown in Fig. 3, the random polymer membrane exhibited a relatively weak ionomer peak located at $\mathrm{q}_{\max } \approx 0.91 \mathrm{~nm}^{-1}$, indicating a low level of aggregation for quaternary ammonium groups and poor ionic clusters formation. As expected, the block polymer membrane showed a clear ionomer peak at $\mathrm{q}_{\max } \approx 0.76 \mathrm{~nm}^{-1}$, which was attributed to the organization of quaternary ammonium hydrophilic ionic clusters, suggesting more obvious phase separation morphology between the hydrophobic and hydrophilic segments. Furthermore, according to Bragg's law $\left(d=2 \pi / \mathrm{q}_{\max }\right)$, the corresponding characteristic distance $d$ could be calculated. Their average distances between ionic clusters were $8.26 \mathrm{~nm}$ for QBPES-60 and $6.90 \mathrm{~nm}$ for QRPES-60, respectively. This result indicated that the block structure formed larger hydrophilic domains and developed more interconnected ion transportation channels. 
Although there were obvious structure features as exhibited in the SAXS profiles, the comprehensive interpretation of membrane morphologies could not only depend on SAXS data, and the high-resolution TEM images were also necessary to further investigate the phase separation morphology in both block and random membranes. The TEM images are shown in Fig. 5. All the membranes exhibited obvious hydrophilic (dark) regions and hydrophobic (bright) regions. The hydrophilic regions in the images are attributed to the formation for aggregation of quaternary ammonium groups, while the bright regions are assigned to the formation of hydrophobic domains composed of polymer backbones. Compared with the random polymer membrane, the block polymer exhibited larger hydrophilic ionic clusters and those hydrophilic domains were interconnected throughout the TEM image. The difference in ionic clusters size in block copolymer was attributed to the hydrophilic sequential block segment as well as the folded and packed polymer main chains relying on the intermolecular interactions. Therefore, this designed block copolymer structure presented more obvious phase separation morphology than the random copolymer. Additionally, as demonstrated in the SAXS profile, the block polymer membrane exhibited more interconnecting ionic channels.

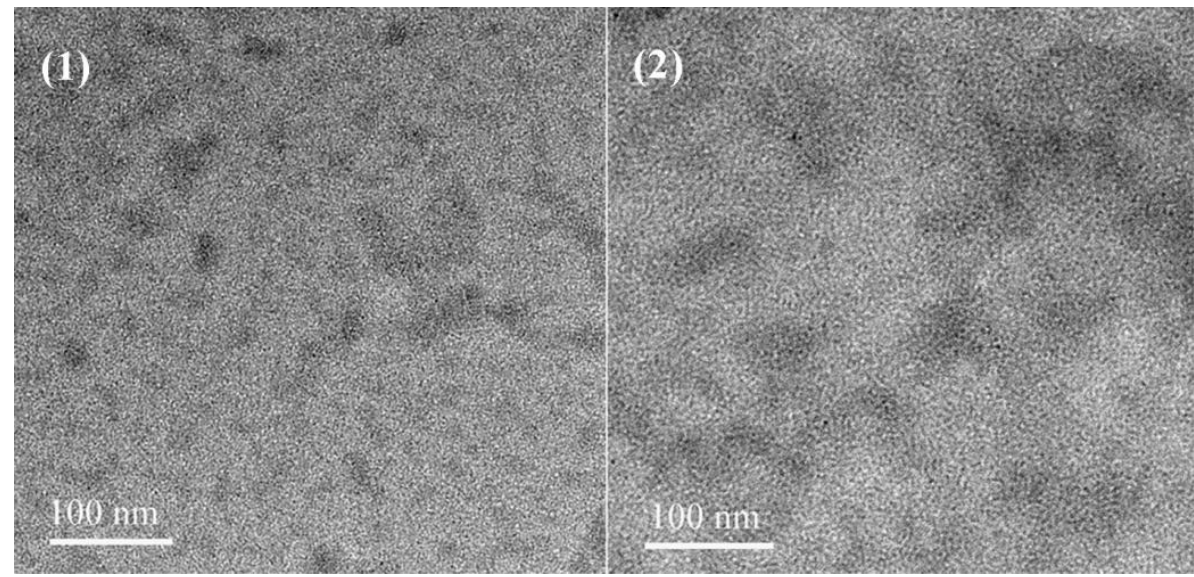


Fig. 5 TEM images of (1) QRPES-60 and (2) QBPES-60.

Table 2

IEC, water uptake, swelling ratio and conductivity of membranes.

\begin{tabular}{ccccccccc}
\hline Sample & \multicolumn{2}{c}{$\begin{array}{c}\text { IEC } \\
(\text { mequiv g-1) }\end{array}$} & \multicolumn{2}{c}{$\begin{array}{c}\text { Water uptake } \\
(\%)\end{array}$} & \multicolumn{2}{c}{$\begin{array}{c}\text { Swelling ratio } \\
(\%)\end{array}$} & \multicolumn{2}{c}{$\begin{array}{c}\text { Conductivity } \\
\left(\mathrm{mS} \mathrm{cm}^{-1}\right)\end{array}$} \\
\cline { 2 - 10 } & $\mathrm{T}^{\mathrm{a}}$ & $\mathrm{E}^{\mathrm{b}}$ & $20^{\circ} \mathrm{C}$ & $60^{\circ} \mathrm{C}$ & $20^{\circ} \mathrm{C}$ & $60^{\circ} \mathrm{C}$ & $60{ }^{\circ} \mathrm{C}$ & $80^{\circ} \mathrm{C}$ \\
\hline QBPES-60 & 1.93 & 1.86 & 42.6 & 49.3 & 7.8 & 8.0 & 40.5 & 52.1 \\
QRPES-60 & 1.93 & 1.89 & 47.2 & 52.9 & 8.6 & 9.1 & 30.0 & 40.0 \\
PSf-ImmOH-70 [31] & 2.06 & 1.94 & - & 129.0 & - & 65.0 & 39.0 & - \\
PAES-10-IMPPO [32] & 2.16 & 2.10 & - & 94.0 & - & 21.0 & 39.0 & 55.0 \\
\hline
\end{tabular}

a IEC in theoretical values.

${ }^{\mathrm{b}}$ IEC from titration.

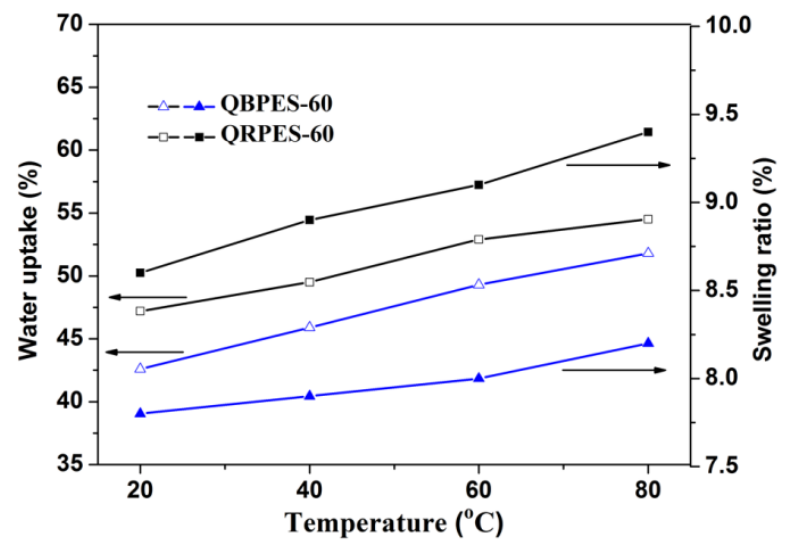

Fig. 6 The water uptake and swelling ratio of QBPES-60 and QRPES-60 at different temperatures.

\subsection{Water uptake and swelling ratio}

The water uptake and swelling ratio are important factors to affect hydroxyl ions transportation and mechanical stability of AEMs. Water molecules dissociate the hydrophilic functionality and promote hydroxide ion transportation [6]. The membrane with a higher water uptake and swelling ratio enables more $\mathrm{OH}^{-}$to transfer through the membrane, leading to higher ion conductivities. On the other hand, excess water uptake and swelling will lead to the loss of dimensional shape and undesirable dimensional change, which affect the membrane mechanical properties and stability 
of the membrane. The water uptake and swelling ratio of QBPES-60 and QRPES-60 membranes measured at different temperatures are summarized in Fig. 6. It can be seen that with the increase of temperature from $20{ }^{\circ} \mathrm{C}$ to $80{ }^{\circ} \mathrm{C}$, water uptake of QBPES-60 and QRPES-60 increased from $42.8 \%$ to $51.8 \%$ and $47.2 \%$ to $54.4 \%$, respectively, while swelling ratio increased from $7.8 \%$ to $8.2 \%$ and $8.6 \%$ to $9.4 \%$, respectively. Moreover, the block QBPES-60 membrane, with a similar IEC to the random QRPES-60 membrane and containing similar densities for hydrophilic groups, absorbed less water than the random membranes. The block membrane was considered to form the hydrophilic/hydrophobic phase-separated structure as exhibited in TEM and SAXS morphology. Consequently, the long sequence of hydrophobic segments embedded around the hydrophilic clusters suppressed excessive water uptake and maintained the stability of the membrane dimension. As in comparison with AEMs with similar poly (arylene ether sulfone) scaffold and IEC values, such as PSf-ImmOH-70 and PAES-10-IMPPO membranes, QBPES-60 and QRPES-60 exhibited lower water uptake and swelling ratio. This result might be attributed to the introduction of rigid phenolphthalein cardo groups.

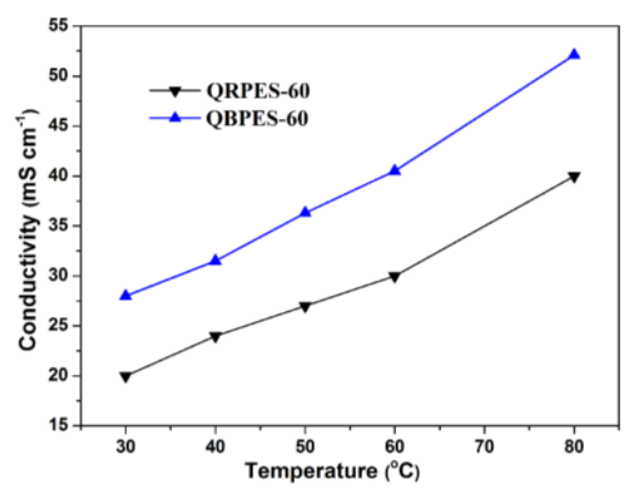

Fig. 7 Temperature dependence of the hydroxide ion conductivities for QBPES-60 
and QRPES-60.

\subsection{Hydroxide conductivity}

The hydroxide conductivity of block and random copolymer membranes were measured in deionized water at temperatures between $30{ }^{\circ} \mathrm{C}$ to $80{ }^{\circ} \mathrm{C}$. As expected, increasing the measurement temperature promoted the increase of hydroxide conductivity (Fig. 7), which is ascribed to the diffusion mechanism and the improvement for thermal motion of $\mathrm{OH}^{-}$in the membrane. Compared to QRPES-60, QBPES-60 exhibited higher conductivity under same condition. For example, the conductivity of the QBPES-60 membrane is $40.5 \mathrm{mS} \mathrm{cm}^{-1}$ at $60{ }^{\circ} \mathrm{C}$, compared to 30.0 $\mathrm{mS} \mathrm{cm}{ }^{-1}$ in the QRPES-60 membrane. The high conductivity can be ascribed to the formation of a micro phase separation structure, as determined by SAXS and TEM. The continuous and ion-rich hydrophilic domains of the QBPES-60 membrane form interconnected ion transport channels and effectively improved the transport of hydroxyl ions across the membranes. Moreover, as in comparison with other reported AEMs with similar values of IEC in Table 2, QBPES-60 exhibited comparable values of hydroxide conductivity on the premise of lower water uptake and swelling ratio, which proved the effectiveness of QBPES-60 in application of AEMs.

\subsection{Alkaline stability of the membranes}

The alkaline stability of AEMs is an essential property for anion exchange membrane fuel cells [9]. The stability of the anion exchange groups in the solid-state membrane structure could be influenced by the physical mobility of the quaternary ammonium ion groups attached to the polymer backbone as well as the hydration state around 
both the $\mathrm{OH}^{-}$and cation groups. In most cases, the degradation pathways for quaternary ammonium groups primarily include eliminations (E2), nucleophilic substitution $\left(\mathrm{S}_{\mathrm{N}} 2\right)$, Stevens or Sommelet-Hauser rearrangements and anion-induced 1,4-eliminations [33]. To evaluate their chemical stabilities, both block QBPES-60 and random QRPES-60 membranes were immersed in 1 mol L $\mathrm{L}^{-1} \mathrm{NaOH}$ at $60{ }^{\circ} \mathrm{C}$ to detect changes in ionic conductivity and ${ }^{1} \mathrm{H}$ NMR spectra. As shown in line (b) of Fig. 8 (1), after the membrane was kept in $1 \mathrm{~mol} \mathrm{~L}^{-1} \mathrm{NaOH}$ for 80 hours, the ${ }^{1} \mathrm{H} \mathrm{NMR}$ spectra of QBPES-60 exhibited a decrease in the signal at $\delta 2.89 \mathrm{ppm}\left(\mathrm{H}_{5}\right)$ that was assigned to the chemical shift of methyl protons in quaternary ammonium groups close to cardo cycle. New signals at $\delta 1.87 \mathrm{ppm}\left(\mathrm{H}_{1^{\prime}}\right)$ and $\delta 1.93 \mathrm{ppm}\left(\mathrm{H}_{2^{\prime}}\right)$ appeared, which can be assigned to the methyl protons of the tertiary amine groups as well as methylene protons attached to tertiary amine groups. Both of these observations are attributed to the $\mathrm{SN}_{2}$ nucleophillic substitution induced by the $\mathrm{OH}^{-}$inside the ion transport channels. In contrast, the signal at $3.15 \mathrm{ppm}\left(\mathrm{H}_{1}\right)$ corresponding to the methyl protons in quaternary ammonium groups far away from cardo cycle remained constant, despite the decrease in conductivity to $21 \mathrm{mS} \mathrm{cm} \mathrm{cm}^{-1}$ as shown in Fig. 9. After being immersed in $\mathrm{NaOH}$ for 240 hours shown in line (c) of Fig. 6 (1), the signal at $\mathrm{H}_{5}(\delta 2.89 \mathrm{ppm})$ disappeared and the signal at $\mathrm{H}_{1}(\delta 3.15 \mathrm{ppm})$ remained constant, while the conductivity decreases to $9 \mathrm{mS} \mathrm{cm}^{-1}$. Overall, the small signals in ${ }^{1} \mathrm{H} \mathrm{NMR}$ spectra of both $80 \mathrm{~h}$ and $240 \mathrm{~h}$ at $\delta$ from 5.40 to $6.10 \mathrm{ppm}$ were assigned to E1 Hofmann Elimination, which occupied little proportion in degradation process. Moreover, the signals at $\delta$ from 7.00 to $8.00 \mathrm{ppm}$ were basically constant, indicating 
the good alkaline stability for copolymer backbone, although the hydrophilic ionic groups gradually degraded. These results can be attributed to good phase-separation structure of the block copolymer, in which the hydrophobic segments around the hydrophilic segments suppress the attack of $\mathrm{OH}^{-}$. Furthermore, the hydrophobic segments can limit the movement of the copolymer backbone, inhibiting $\mathrm{OH}^{-}$attack of the hydrophilic quaternary ammonium groups, as confirmed by low water uptake and swelling ratio (Table 2).

As shown in Fig. 8 (2), the ${ }^{1} \mathrm{H}$ NMR spectra for QRPES-60 also showed obvious changes. After being immersed in $\mathrm{NaOH}$ for 80 hours, the signals at $\mathrm{H}_{1}(\delta 3.15 \mathrm{ppm})$ and $\mathrm{H}_{5}(\delta 2.89 \mathrm{ppm})$ for the methyl protons in quaternary ammonium groups sharply decreased and the signals at $\delta 1.88 \mathrm{ppm}$ and $\delta 1.93 \mathrm{ppm}$ for the methyl protons $\left(\mathrm{H}_{1^{\prime}}\right.$ and $\mathrm{H}_{2^{\prime}}$ ) in tertiary amine groups could be observed due to the $\mathrm{SN}_{2}$ nucleophillic substitution under alkaline conditions, while the membrane showed low ion conductivity of $13 \mathrm{mS} \mathrm{cm} \mathrm{cm}^{-1}$ exhibited in Fig. 9. After being immersed in $\mathrm{NaOH}$ for 240 hours, the signals at $\delta 3.01 \mathrm{ppm}$ and $\delta 2.75 \mathrm{ppm}\left(\mathrm{H}_{1}\right.$ and $\left.\mathrm{H}_{5}\right)$ basically disappeared, and the ion conductivity decreased to $6 \mathrm{mS} \mathrm{cm}^{-1}$. Similarly, the small signals at $\delta$ from 5.30 to $6.00 \mathrm{ppm}$ were assigned to E1 Elimination and this degradation pathway also occupied little proportion. The membrane copolymer backbone still kept stable, judging from the constant multiplet at $\delta$ from 7.00 to 8.00 ppm. These experimental results demonstrated that the random bis-quaternary ammonium copolymer QRPES-60 was unstable in $\mathrm{NaOH}$ and they could be easily decomposed by $\mathrm{SN}_{2}$ nucleophillic substitution induced by the $\mathrm{OH}^{-}$inside the 
membranes. In contrast, the block QBPES-60 membrane exhibited a relatively stable structure, despite showing certain degradation in the quaternary ammonium groups. The well-designed block polymer can not only endow the membrane with the distinct hydrophilic/hydrophobic phase separation structure to improve membrane ion conductivity, but also weaken the $\mathrm{SN}_{2}$ nucleophilic substitution and enhance the alkaline stability.

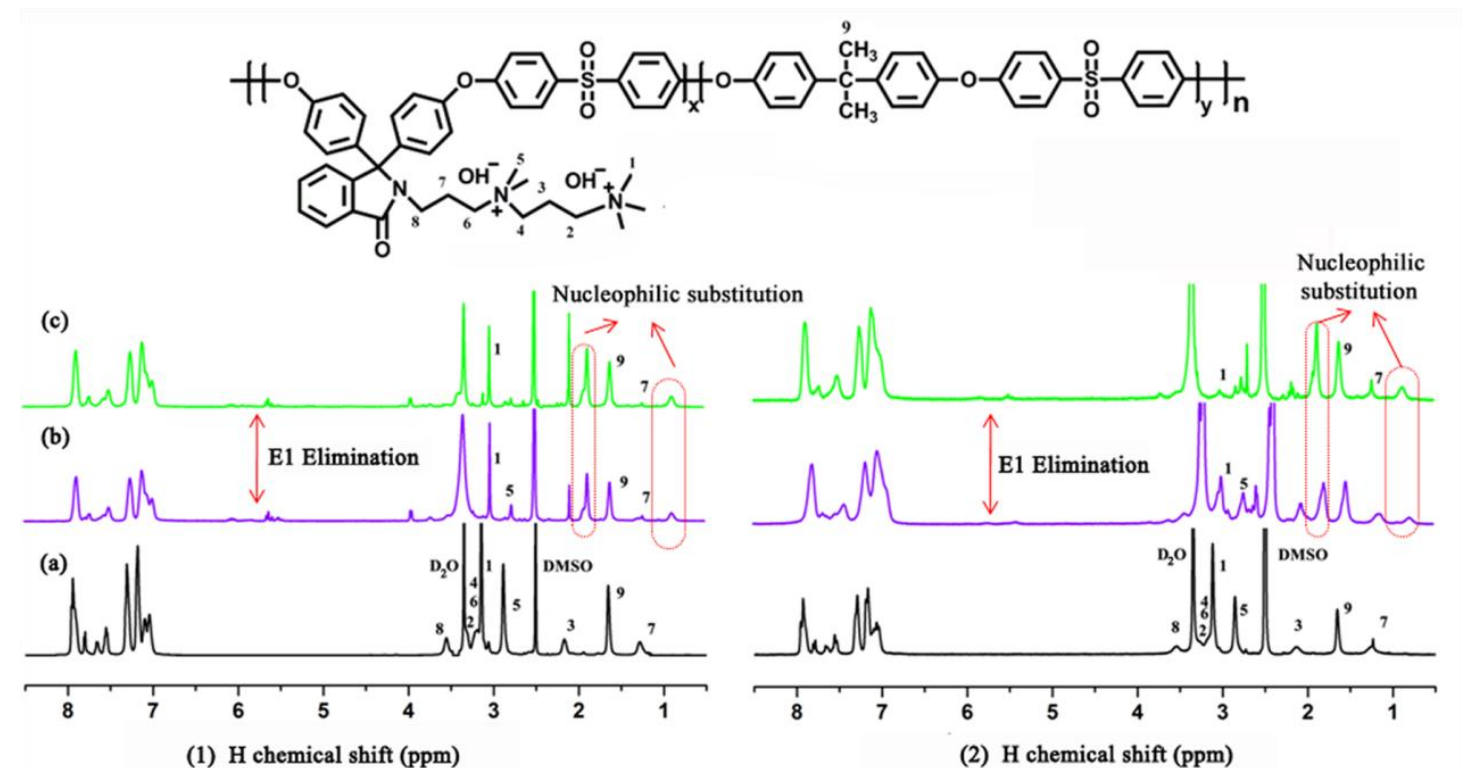

Fig. 8 The changes of ${ }^{1} \mathrm{H}$ NMR spectra before and after the membranes (1) QBPES-60 (2) QRPES-60 were immersed in $1 \mathrm{~mol} \mathrm{~L}^{-1} \mathrm{NaOH}$ at $60{ }^{\circ} \mathrm{C}$ for certain hours (a) black line represents $0 \mathrm{~h}$ (b) purple line represents $80 \mathrm{~h}$ (c) green line represents $240 \mathrm{~h}$. 


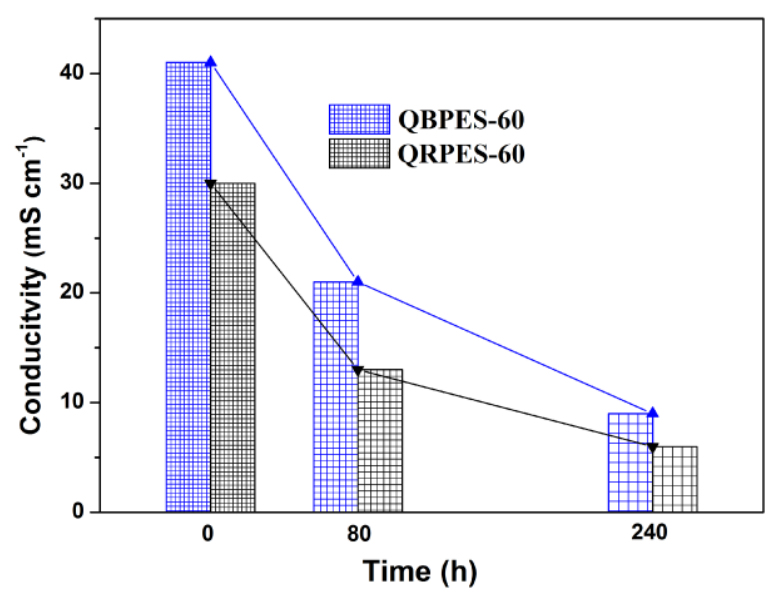

Fig. 9 Conductivity changes at $60{ }^{\circ} \mathrm{C}$ after the membranes were immersed in $1 \mathrm{~mol} \mathrm{~L}^{-1}$ $\mathrm{NaOH}$ at $60{ }^{\circ} \mathrm{C}$ for certain hours.

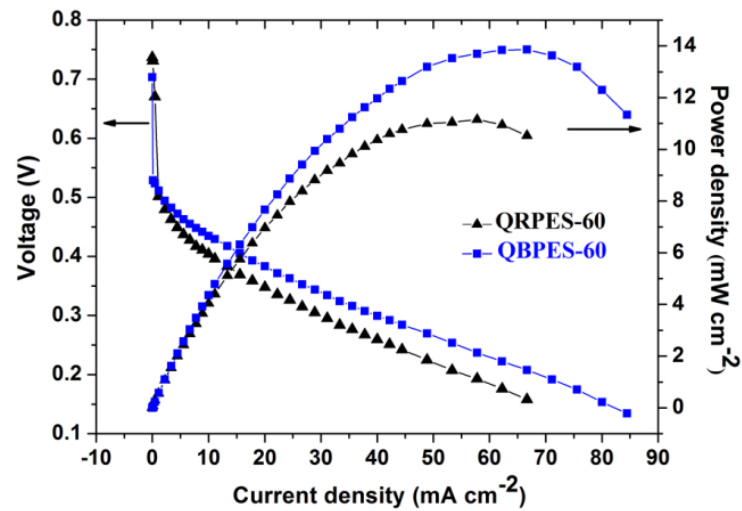

Fig. 10 Polarization and power density curves of AMFC assembled with QRPES-60 and QBPES-60 membrane measured at $40{ }^{\circ} \mathrm{C}$.

\subsection{Single fuel cell evaluation}

The membrane electrode assembly (MEA) was examined using QRPES-60 and QBPES-60 for a single cell test of DMFC according to the literature method [31]. As shown in Fig. 10, the DMFC assembled with QRPES-60 membrane exhibited a peak power density of $11.15 \mathrm{~mW} \mathrm{~cm}^{2}$, while the DMFC assembled with QBPES-60 membrane exhibited a higher peak power density of $13.86 \mathrm{~mW} \mathrm{~cm}{ }^{-2}$. The better cell performance of QBPES-60 membrane than QRPES-60 membrane above is mainly 
due to its higher conductivity. Furthermore, as in comparison with imidazolium functionalized PSf-ImmOH-70 membrane in our previous work [31], QBPES-60 and QRPES-60 in a similar values of IEC exhibited higher power density than PSf-ImmOH-70 (6.00 $\left.\mathrm{mW} \mathrm{\textrm {cm } ^ { - 2 }}\right)$ under same test conditions, which is possibly attributed to the higher conductivity in same condition.

\section{Conclusions}

In summary, we synthesized bis-quaternary ammonium and flexible aliphatic side chain random and block copolymers (QRPES-60 and QBPES-60). The block structure is effective in improving the ionic conductivity and alkaline ability of AEMs. The block copolymer QBPES-60, possessing a more obvious phase-separated structure and ion cluster formation, provides ionic channels for hydroxyl ions transportation and contributes to higher conductivity than the random copolymer QRPES-60 under the same conditions. Moreover, the block anion exchange membrane shows better alkaline stability than the random membrane due to its low water uptake as well as the good suppression of hydrophobic phase. For example, the retention of ionic conductivity for the block membrane was $51 \%$, compared to $43 \%$ for the random membrane in alkaline stability testing under $1 \mathrm{M} \mathrm{NaOH}$ at $60{ }^{\circ} \mathrm{C}$ for $80 \mathrm{~h}$. Based on the performance above, the combined results indicated effective strategy toward high-performance anion membrane materials.

\section{Acknowledgment}

The authors gratefully acknowledge the National Basic Research Program of China (No. 2012CB932802, 2015CB655302), the National Science Foundation of China 
(No. 21304092, 51133008, 51473163 and 51321062), and the Development of

Scientific and Technological Project of the Jilin Province (No. 20160101316JC) for

financial support.

\section{References}

[1] A.N. Lai, L.S. Wang, C.X. Lin, Y.Z. Zhuo, Q.G. Zhang, A.M. Zhu, Q.L. Liu, Phenolphthalein-based Poly(arylene ether sulfone nitrile)s Multiblock Copolymers As Anion Exchange Membranes for Alkaline Fuel Cells, ACS Appl. Mater. Interfaces 7 (2015) 8284-8292.

[2] J. Cheng, G. He, F. Zhang, A mini-review on anion exchange membranes for fuel cell applications: Stability issue and addressing strategies, Int. J. Hydrog. Energy 40 (2015) 7348-7360.

[3] J.R. Varcoe, P. Atanassov, D.R. Dekel, A.M. Herring, M.A. Hickner, P.A. Kohl, A.R. Kucernak, W.E. Mustain, K. Nijmeijer, K. Scott, T. Xu, L. Zhuang, Anion-exchange membranes in electrochemical energy systems, Energy Environ. Sci. 7 (2014) 3135-3191.

[4] F. Gu, H. Dong, Y. Li, Z. Sun, F. Yan, Base Stable Pyrrolidinium Cations for Alkaline Anion Exchange Membrane Applications, Macromolecules 47 (2014) 6740-6747.

[5] P.Y. Xu, K. Zhou, G.L. Han, Q.G. Zhang, A.M. Zhu, Q.L. Liu, Effect of fluorene groups on the properties of multiblock poly(arylene ether sulfone)s-based anion-exchange membranes, ACS Appl. Mater. Interfaces 6 (2014) 6776-6785.

[6] J. Wang, Z. Zhao, F. Gong, S. Li, S. Zhang, Synthesis of Soluble Poly(arylene ether sulfone) Ionomers with Pendant Quaternary Ammonium Groups for Anion Exchange Membranes, Macromolecules 42 (2009) 8711-8717.

[7] F. Zhang, H. Zhang, C. Qu, Imidazolium functionalized polysulfone anion exchange membrane for fuel cell application, J. Mater. Chem. 21 (2011) 12744-12752.

[8] M. Tanaka, M. Koike, K. Miyatake, M. Watanabe, Anion Conductive Aromatic Ionomers Containing Fluorenyl Groups, Macromolecules 43 (2010) 2657-2659.

[9] D. Chen, M.A. Hickner, Degradation of imidazolium- and quaternary ammonium-functionalized poly(fluorenyl ether ketone sulfone) anion exchange membranes, ACS Appl. Mater. Interfaces 4 (2012) 5775-5781.

[10] D. Chen, M.A. Hickner, Ion Clustering in Quaternary Ammonium Functionalized Benzylmethyl Containing Poly(arylene ether ketone)s, Macromolecules 46 (2013) 9270-9278.

[11] Z. Zhao, J, Wang, S. Li, S. Zhang, Synthesis of multi-block poly(arylene ether sulfone) copolymer membrane with pendant quaternary ammonium groups for alkaline fuel cell, J. Power Sources 196 (2011) 4445-4450.

[12] A. Jasti, V.K. Shahi, Multi-block poly(arylene ether)s containing pre-choloromethylated bisphenol: anion conductive ionomers, J. Mater. Chem. A 1 (2013) 6134-6137.

[13] N. Yokota, M. Shimada, H. Ono, R. Akiyama, E. Nishino, K. Asazawa, J. Miyake, M. Watanabe,

K. Miyatake, Aromatic Copolymers Containing Ammonium-Functionalized Oligophenylene Moieties as Highly Anion Conductive Membranes, Macromolecules 47 (2014) 8238-8246.

[14] N. Li, Y. Leng, M.A. Hickner, C.Y. Wang, Highly stable, anion conductive, comb-shaped copolymers for alkaline fuel cells, J. Am. Chem. Soc. 135 (2013) 10124-10133.

[15] Z. Yang, J. Hou, X. Wang, L. Wu, T. Xu, Highly Water Resistant Anion Exchange Membrane for 
Fuel Cells, Macromol. Rapid Commun. 36 (2015) 1362-1367.

[16] M.R. Hibbs, C.H. Fujimoto, C.J. Cornelius, Synthesis and Characterization of Poly(phenylene)-Based Anion Exchange Membranes for Alkaline Fuel Cells, Macromolecules 42 (2009) 8316-8321.

[17] Y. Li, Y. Liu, A.M. Savage, F.L. Beyer, S. Seifert, A.M. Herring, D.M. Knauss, Polyethylene-Based Block Copolymers for Anion Exchange Membranes, Macromolecules 48 (2015) 6523-6533.

[18] M.A. Hossain, Y. Lim, S. Lee, H. Jang, S. Choi, Y. Jeon, J. Lim, W.G. Kim, Comparison of alkaline fuel cell membranes of random \& block poly(arylene ether sulfone) copolymers containing tetra quaternary ammonium hydroxides, Int. J. Hydrog. Energy 39 (2014) 2731-2739.

[19] K.M. Lee, M. Litt, P.N. Pintauroc, Alkaline fuel cell membranes from xylylene block ionenes, J. Membr. Sci. 383 (2011) 254-261.

[20] Y. Liu, J. Wang, Y. Yang, T.M. Brenner, S. Seifert, Y. Yan, M.W. Liberatore, A.M. Herring, Anion Transport in a Chemically Stable, Sterically Bulky $\alpha-C$ Modified Imidazolium Functionalized Anion Exchange Membrane, J. Phys. Chem. C 118 (2014) 15136-15145.

[21] Q. Ge, J. Ran, J. Miao, Z. Yang, T. Xu, Click Chemistry Finds Its Way in Constructing an Ionic Highway in Anion-Exchange Membrane, ACS Appl. Mater. Interfaces 7 (2015) 28545-28553.

[22] M. Tanaka, K. Fukasawa, E. Nishino, S. Yamaguchi, K. Yamada, H. Tanaka, B. Bae, K. Miyatake, M. Watanabe, Anion conductive block poly(arylene ether)s: synthesis, properties, and application in alkaline fuel cells, J. Am. Chem. Soc. 133 (2011) 10646-10654.

[23] A.H.N. Rao, H.J Kim, S. Nam, T.H. Kima, Cardo poly(arylene ether sulfone) block copolymers with pendant imidazolium side chains as novel anion exchange membranes for direct methanol alkaline fuel cell, Polymer 54 (2013) 6918-6928.

[24] Q. Zeng, Q. Liu, I. Broadwell, A. Zhu, Y. Xiong, X. Tu, Anion exchange membranes based on quaternized polystyrene-block-poly(ethylene-ran-butylene)-block-polystyrene for direct methanol alkaline fuel cells, J. Membr. Sci. 349 (2010) 237-243.

[25] X. Li, Q. Liu, Y. Yu, Y. Meng, Synthesis and properties of multiblock ionomers containing densely functionalized hydrophilic blocks for anion exchange membranes, J. Membr. Sci. 467 (2014) 1-12.

[26] H.S. Dang, P. Jannasch, Exploring Different Cationic Alkyl Side Chain Designs for Enhanced Alkaline Stability and Hydroxide Ion Conductivity of Anion-Exchange, Macromolecules 48 (2015) 5742-5751

[27] Y. He, J. Pan, L. Wu, Y. Zhu, X. Ge, J. Ran, Z. Yang, T. Xu, A Novel Methodology to Synthesize Highly Conductive Anion Exchange Membranes, Sci. Rep. 5 (2015) 13417.

[28] A.D. Mohanty, C. Bae, Mechanistic analysis of ammonium cation stability for alkaline exchange membrane fuel cells, J. Mater. Chem. A 2 (2014) 17314-17320.

[29] Q. Zhang, Q. Zhang. J. Wang, S. Zhang, S. Li, Synthesis and alkaline stability of novel cardo poly(aryl ether sulfone)s with pendent quaternary ammonium aliphatic side chains for anion exchange membranes, Polymer 51 (2010) 5407-5416.

[30] J. Wang, J. Wang, S. Li, S. Zhang, Poly(arylene ether sulfone)s ionomers with pendant quaternary ammonium groups for alkaline anion exchange membranes: Preparation and stability issues, J. Membr. Sci. 368 (2011) 246-253.

[31] Y. Yang, J. Wang, J. Zheng, S. Li, S. Zhang, A stable anion exchange membrane based on imidazolium salt for alkaline fuel cell, J. Membr. Sci. 467 (2014) 48-55.

[32] C. Lin, Y. Zhuo, A. Lai, Q. Zhang, A. Zhu, M. Ye, Q. Liu, Side-chain-type anion exchange 
membranes bearing pendent imidazolium-functionalized poly(phenylene oxide) for fuel cells, J. Membr. Sci. 513 (2016) 206-216.

[33] S.A. Nuñez, C. Capparelli, M.A. Hickner, N-Alkyl Interstitial Spacers and Terminal Pendants Influence the Alkaline Stability of Tetraalkylammonium Cations for Anion Exchange Membrane Fuel Cells, Chem. Mater. 28 (2016) 2589-2598. 


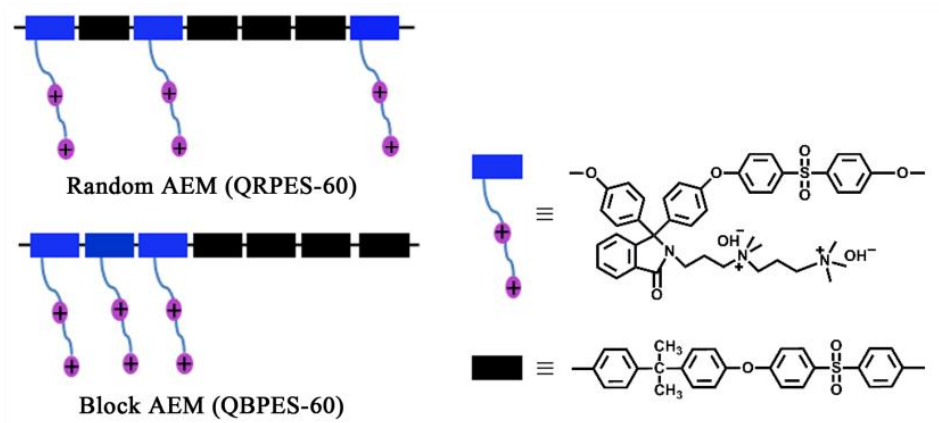

QBPES-60 exhibits higher conducivity and alkaline stability.

Graphical Abstract 